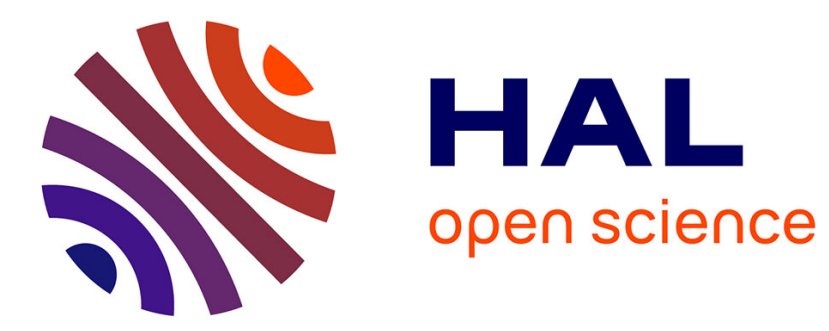

\title{
Anionic redox processes for electrochemical devices
}

\author{
Alexis Grimaud, W. T Hong, Y. Shao-Horn, J.-M. Tarascon
}

\section{To cite this version:}

Alexis Grimaud, W. T Hong, Y. Shao-Horn, J.-M. Tarascon. Anionic redox processes for electrochemical devices. Nature Materials, 2016, 15 (2), pp.121-126. 10.1038/nmat4551 . hal-03315777

\section{HAL Id: hal-03315777 \\ https://hal.science/hal-03315777}

Submitted on 6 Aug 2021

HAL is a multi-disciplinary open access archive for the deposit and dissemination of scientific research documents, whether they are published or not. The documents may come from teaching and research institutions in France or abroad, or from public or private research centers.
L'archive ouverte pluridisciplinaire HAL, est destinée au dépôt et à la diffusion de documents scientifiques de niveau recherche, publiés ou non, émanant des établissements d'enseignement et de recherche français ou étrangers, des laboratoires publics ou privés. 


\section{Anionic redox processes for electrochemical devices}

Grimaud A. 1,2,3 Hong, W.T.4 Shao-Horn Y.,4, and Tarascon J.-M*1,2,5,6

1. Chimie du Solide et de l'Energie, FRE 3677, Collège de France, 75231 Paris Cedex 05, France

2. Réseau sur le Stockage Electrochimique de l'Energie (RS2E), FR CNRS 3459, 80039 Amiens Cedex, France

3. Department of Mechanical Engineering, Massachusetts Institute of Technology, Cambridge, MA 02139, USA

4. Departmental of Materials Science and Engineering, Massachusetts Institute of Technology, Cambridge, MA 02139, USA

5. ALISTORE-European Research Institute, FR CNRS 3104, 80039 Amiens, France

6. Sorbonne Universités - UPMC Univ Paris 06, 75005 Paris, France

- Corresponding author : jean-marie.tarascon@college-de-France.fr

Understanding and controlling the anionic redox processes is pivotal for the design of new Li-ion battery and water splitting materials. 
Redox chemistry provides the fundamental basis for numerous energy-related electrochemical devices, among which are electrolyzers, fuel cells and batteries. Throughout its history, the Li-ion battery technology (LIB) has relied on cationic redox reactions as the primary source of energy storage capacity. This is no longer true with the recent discovery of Li-driven reversible formation of $\left(\mathrm{O}_{2}\right)^{\mathrm{n}-}$ species in new layered oxides that led to staggering increases in energy storage capacity. Such findings could provide a transformative approach for creating advanced energy materials for not only lithium storage but also for the oxygen evolution reaction (OER), as both involve (O-O) bond formation. The exploration of these new opportunities calls for a better understanding and rationalization of the science underpinning anionic redox activity. This commentary aims to raise the energy community's awareness of the benefits that this new vision could bring to materials design for energy storage and conversion applications.

Li-ion batteries are energy storage devices based on positive and negative electrodes that operate via an insertion/de-insertion process associated with the sole redox activity of $3 d$-metal cations in the positive electrode. The first commercialized Li-ion cells used $\mathrm{LiCoO}_{2}$ as a positive electrode, and this layered material remained the "stellar electrode" for two decades. By partially substituting Co with $\mathrm{Ni}$ and $\mathrm{Mn}$ within the $\mathrm{MO}_{2}$ layers, chemists have successfully prepared $\mathrm{Li}\left(\mathrm{Ni}_{1 / 3} \mathrm{Mn}_{1 / 3} \mathrm{Co}_{1 / 3}\right) \mathrm{O}_{2},{ }^{1}$ referred to as $\mathrm{NMC}$, which is the most attractive electrode today since it displays the highest capacity $(200 \mathrm{mAh} / \mathrm{g})$. The additional substitution of $\mathrm{Co}$ with $\mathrm{Li}$ within the $\mathrm{MO}_{2}$ layers has recently led to materials made of $\mathrm{Ni}$, Co and $\mathrm{Mn}$ with $\mathrm{Li}$ in excess $\left(\mathrm{Li}\left[\mathrm{Li}_{0.2} \mathrm{Ni}_{0.13} \mathrm{Mn}_{0.54} \mathrm{Co}_{0.13}\right] \mathrm{O}_{2}\right)^{2,3}$ called Li-rich $\mathrm{NMC}$, which shows capacities $(270 \mathrm{mAh} / \mathrm{g})$ exceeding theoretical ones based on the redox activity of the cationic network. Typically, such compounds release $\mathrm{Li}$ via an oxidation process manifested as a staircase voltage curve ending with a high voltage plateau $(\sim 4.5 \mathrm{~V})$, and re-absorb Li via a reduction process with an S-type voltage profile. ${ }^{3,4}$ Such a voltage-composition profile differs drastically from classical insertion compounds with charge and discharge curves that mirror nicely.

Attempts to explain such a drastic difference have failed due to the complexity of the Li-rich system, which enlists several cationic $\left(\mathrm{Ni}^{\mathrm{n}+}, \mathrm{Co}^{\mathrm{m}+}, \mathrm{Mn}^{\mathrm{z}}\right)$ redox centers. Back in 2013, we removed this ambiguity in redox center via a new chemical approach rooted in the design of layered $\mathrm{Li}_{2} \mathrm{Ru}_{1-\mathrm{y}} \mathrm{Sn}_{\mathrm{y}} \mathrm{O}_{3}$ as model compounds, which include a single $\mathrm{Ru}^{4+}$ redox center. ${ }^{5}$ In contrast to early beliefs, a study of these high-capacity electrodes $(260 \mathrm{mAh} / \mathrm{g})$ by complementary XPS and EPR measurements demonstrated direct evidence for Li-driven, reversible formation of peroxo-like $\left(\mathrm{O}_{2}\right)^{n-}$ species in these materials, ${ }^{5,6}$ hence confirming what we speculated as early as $2000{ }^{7,8}$ On that basis, their high capacity was explained as due to cumulative cationic $\left(\mathrm{M}^{\mathrm{n}+} \leftrightarrow \mathrm{M}^{\mathrm{n}+1}\right)$ and anionic $\left(2 \mathrm{O}^{2-} \leftrightarrow\left(\mathrm{O}_{2}\right)^{n-}\right)$ reversible redox processes. ${ }^{6,9,10}$ This substantially boosts the limit of the Li-ion technology by raising the capacity limit, usually believed to be $1 \mathrm{e}^{-}$per $3 d$-metal. Moreover, it enables the use of $4 d$ rather than $3 d$ metals, so far disregarded because of their heavy weight, opening a new line in the periodic table with which chemists can establish new phases. This finding has received worldwide attention with the emergence of novel materials. For example, a new layered compound $\mathrm{Li}_{4} \mathrm{Fe}_{\mathrm{y}} \mathrm{Nb}_{\mathrm{z}} \mathrm{O}_{3}$ - which uses a $4 d$-metal ( $\mathrm{Nb}$ instead of $\mathrm{Ru}$ ) and shows a reversible capacity of $300 \mathrm{mAh} / \mathrm{g}$ involving an anionic redox process - has recently been uncovered, ${ }^{11}$ and there are a number of other materials in the pipeline. Na-based electrodes benefiting from anionic redox activity were recently reported as well. ${ }^{12}$

Anionic redox can also play an integral role in catalyzing oxygen electrocatalysis, especially for the oxygen evolution reaction (OER). One prevailing mechanism for oxygen electrocatalysis on transition metal oxides such as rutiles or perovskites derives from that of metal catalysts. ${ }^{13,14}$ Hence, special attention has been paid to the oxygen binding strength on the surface of catalysts following the Sabatier principle: the most active catalyst binds oxygen to the surface neither too strongly nor too weakly. Therefore, tuning the surface electronic structure of oxides has been shown to enhance the catalytic activity. ${ }^{15,16}$ Over the last few years, this view has begun to be challenged by a few observations 
highlighting the importance of the bulk oxide electronic structure in catalyzing oxygen electrocatalysis through the possible involvement of lattice oxygen in the OER process. ${ }^{17-21}$ In 2013 , we demonstrated the relative energy of the oxygen $p$ band vs. the Fermi level in transition metal oxide perovskites as an activity and stability descriptor for OER catalysts. ${ }^{22}$ This finding emphasizes the need for shifting the oxygen $p$ band closer to the Fermi level, as it can trigger the redox activity of the lattice oxygen to increase the oxygen reduction ${ }^{16}$ and evolution ${ }^{23}$ reaction (ORR/OER) activities of perovskites. The implication of lattice oxygen in oxygen electrocatalysis is not restricted to water splitting, but has also been discussed for high-temperature solid oxide fuel cell (SOFC) materials. For example, Lee et al. in 2011 reported the existing correlation between surface oxygen exchange kinetics for perovskites with the oxygen $p$ band center relative to the Fermi level. ${ }^{24}$ This idea has been further developed by Mueller et al. in $2015^{25}$ by demonstrating that lattice oxygen anions are a significant redox partner to $\mathrm{O}_{2(\mathrm{~g})}$ on the surface of SOFC materials. This timely finding, which coincided with the need for strong metal $d$ - and oxygen $p$-band overlap to trigger the anionic redox activity for enabling high-capacity layered oxide electrodes, is indicative of a possible synergy between electrocatalysis and battery materials.

In this paper, we attempt to describe the fundamental science behind this apparent synergy so as to set a comprehensive scientific platform for enabling the design of materials at the crossroads of batteries and water splitting. Based on our present state of understanding, key parameters for the formation of (O-O) bonds and $\left(\mathrm{O}_{2}\right)^{n-}$ species will be reviewed. The presence of such species as a common denominator in battery and oxygen electrocatalysis materials will be discussed together with the opportunities that it offers. Lastly, research directions that could emerge from this new outlook on electrodes and electrocatalysts will be proposed.

\section{Anionic redox processes within insertion oxide electrodes}

The amount of $\mathrm{Li}^{+}$uptake by an insertion $\mathrm{Li}_{\mathrm{x}} \mathrm{M}_{\mathrm{n}} \mathrm{X}_{\mathrm{y}}$ compound and the potential at which it inserts $\mathrm{Li}^{+}$depends on both material crystal and electronic structures. Its redox potential is mainly related to the iono-covalence of the $\mathrm{M}-\mathrm{X}$ bond, with the highest potential for $\mathrm{M}-\mathrm{X}$ bonds having the largest ionicity. ${ }^{26}$ One should recall that a solid band structure is made of one low-lying band arising from bonding M-X electronic levels (MX in Figure 1) and one high-lying band arising from antibonding $\mathrm{M}-\mathrm{X}$ states $\left(\mathrm{MX}^{*}\right.$ in Figure 1). These two bands are separated by one band of purely nonbonding ligand states. What we classically describe as metal $d$ band is in fact the MX*. Owing to the high ionicity of insertion oxides, a schematic drawing of their density of states places the $3 d$ metal cationic band well above the $p$ anionic band (Fig. 1 left panel). This implies that when $\mathrm{Li}^{+}$enters or leaves vacancies in a host insertion oxide, the $d$ metal levels are providing or releasing the associated electrons, hence acting as redox centers. It then becomes a well-established belief that the insertion reaction in oxides solely involves cationic redox processes, since the $d$ and $p$ bands are well separated.
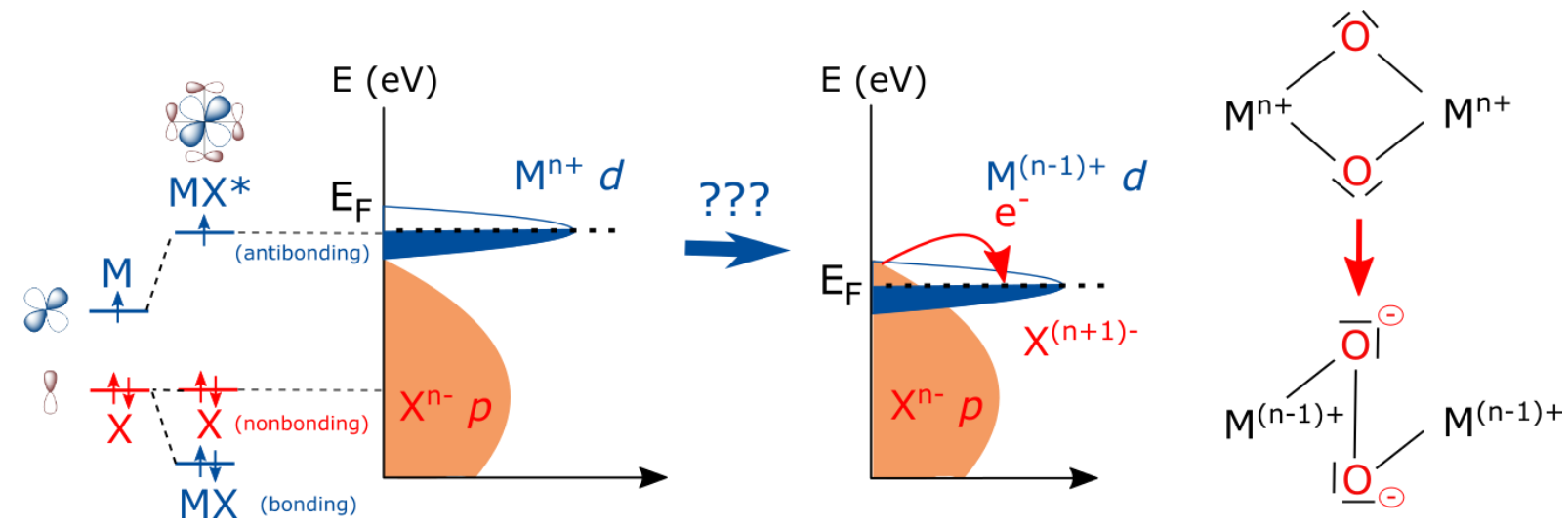
Figure. 1. Triggering the anionic redox process in a solid. Schematic of the transition metal ligand (MX) band structure made from an antibonding $\mathrm{MX}^{*}$ states (described as $d$ band), a nonbonding purely ligand $X$ states (described as $p$ band) and a bonding MX state (this band is very low in energy and not involved in the redox, it is therefore not represented for sake of clarity). The scheme shows that when the cationic $d$ band enters the ligand $p$ band, ligand holes can be formed by transferring electrons to the metal, which is then reduced. On the right is represented the formation of peroxo-like species in transition metal oxides: once formed, ligand holes can be stabilized in very specific cases by the modification of the oxygen environment and the formation of O-O bond (two oxygen sharing their ligand hole). This case differs from a redox involving only the MO* states, that can have an oxygen weight due to the covalency of the M-O bond, which remains mostly cationic.

Such a simplistic view is no longer true when the anionic $p$ band becomes close to or even penetrates into the metal $d$ band (Fig. 1 right panel). This usually occurs for insertion compounds in which $\mathrm{O}$ ligands are replaced by less electronegative ones $(\mathrm{S}>\mathrm{Se}>\mathrm{Te})$, as discussed by $\mathrm{J}$. Rouxel back in the 1990's in a seminal paper "The anion-cation redox competition in solids." ${ }^{27}$ In this case, there is a stronger $\mathrm{M}(d)-\mathrm{X}(p)$ overlap, with the feasibility to trigger anionic redox processes through the reversible formation of $\left(\mathrm{S}_{2}\right)^{\mathrm{n}-}$ species, as experimentally verified in $\mathrm{Li}_{\mathrm{x}} \mathrm{FeS}_{2} \cdot{ }^{28}$ The chance of reaching such a situation with oxides is at first counterintuitive. Nevertheless, a first example comes from the field of superconducting materials with the experimental evidence in the 1980's of oxygen holes due to a high $\mathrm{M}(d)-\mathrm{X}(p)$ hybridization in the high $\mathrm{T}_{\mathrm{c}}$ superconducting cuprates. ${ }^{29}$ A similar $\mathrm{M}(d)-\mathrm{X}(p)$ hybridization was proposed back in 1999 to account for the feasibility of preparing the fully delithiated $\mathrm{CoO}_{2}$ phase, ${ }^{7}$ but not accepted by the battery community without direct experimental proof. Fifteen years of controversies passed before the existence of redox anionic activity was experimentally demonstrated in the Li-rich layered oxides. ${ }^{5}$ So indeed, the presence of a redox active anionic network can exist with oxides. It implies the presence of a framework within which the ligand $\mathrm{O}^{2-}$ can become more electropositive than the $\mathrm{M}^{\mathrm{n}+}$ cation. This scenario can occur in a highly covalent network where the transition metal $d$ band penetrates the ligand $p$ band so that electrons from the $\mathrm{O} p$ band are poured into the $d$ band (Fig. 1); this leaves behind holes that can eventually create oxygenated $\left(\mathrm{O}_{2}\right)^{n-}$ species by modifying their environment. ${ }^{30}$ Tuning the relative positions of the cationic $d$ and anionic $p$ levels offers chemists another dimension to design high-capacity electrode materials, cumulating both cationic and anionic redox capacities.

Two options can be explored to increase the covalence of the oxide framework. One relies on replacing oxygen by less electronegative ligands, such as $\mathrm{X}=\mathrm{S}$, Se or Te, so as to raise the energy level of the $\mathrm{X} p$ band and increase the hybridization. For a given ligand, the other option consists of lowering the energy of the transition metal (TM) $d$ orbitals by using a more electronegative metal. This is done, for instance, by replacing $\mathrm{Mn}$ by $\mathrm{Ru}$ in $\mathrm{Li}_{2} \mathrm{MO}_{3}$ since the overlap is stronger for $\mathrm{Ru}(4 d)-\mathrm{O}(2 p)$ than for $\mathrm{Mn}(3 d)-\mathrm{O}(2 p)$ because the atomic $\mathrm{Ru}(4 d)$ orbitals are more spatially expanded and less correlated than the $\mathrm{Mn}(3 d)$ orbitals. ${ }^{31} \mathrm{~A}$ fine-tuning of these qualitative trends can be made by computation, ${ }^{31}$ but another critical issue for the selected configurations regards the stability of the Lidriven oxygenated species $\left(\mathrm{O}_{2}\right)^{n-}$ formed at high voltages against $\mathrm{O}_{2(\mathrm{~g})}$ release (e.g formation of oxygen vacancies). ${ }^{30} \mathrm{We}$ should indeed recall that the electrochemical removal of $\mathrm{Li}^{+}$from the Li-rich $\mathrm{Li}\left[\mathrm{Li}_{0.2} \mathrm{Ni}_{0.14} \mathrm{Co}_{0.13} \mathrm{Mn}_{0.54}\right] \mathrm{O}_{2}$ phase triggers the formation of $\left(\mathrm{O}_{2}\right)^{n-}$ species at $4.5 \mathrm{~V}$; a part of which recombines into $\mathrm{O}_{2}$ leading to an irreversible capacity loss and an electrode material with a surface depleted in oxygen. ${ }^{32}$ To grasp further insight into the formations of $\left(\mathrm{O}_{2}\right)^{n-}$ species and their eventual recombination into $\mathrm{O}_{2(\mathrm{~g})}$, we exploited the rich $\mathrm{Li}_{2} \mathrm{MO}_{3}$ family (which accommodates several single metal element members) and its derived family of general formula $\mathrm{Li}_{4} \mathrm{MM}^{\prime} \mathrm{O}_{6}$ (which can contain different metals as long as the sum of the oxidation states of $M$ and $M^{\prime}$ is equal to eight). We used this 
chemical playground and prepared several phases $\mathrm{Li}_{4} \mathrm{NiTeO}_{6},{ }^{33} \mathrm{Li}_{4} \mathrm{FeTeO}_{6},{ }^{34} \mathrm{Li}_{4} \mathrm{FeSbO}_{6},{ }^{35}$ $\mathrm{Li}_{4} \mathrm{Ru}_{1.5} \mathrm{Sn}_{0.5} \mathrm{O}_{6}{ }^{5}{ }^{5} \mathrm{Li}_{4} \mathrm{Ru}_{1.5} \mathrm{Ti}_{0.5} \mathrm{O}_{6},{ }^{36}$ to check the influence of both the cationic distribution and $\mathrm{M} / \mathrm{M}$ ' ratio on the formation of $\left(\mathrm{O}_{2}\right)^{n-}$ species, as well as on the structural stability towards $\mathrm{O}_{2(\mathrm{~g})}$ release. No anionic redox activity was detected for $\mathrm{Li}_{4} \mathrm{NiTeO}_{6}{ }^{33}$ while $\mathrm{O}_{2(\mathrm{~g})}$ release was solely observed for $\mathrm{Li}_{4} \mathrm{Fe}_{0.56} \mathrm{TeO}_{6}{ }^{34}$ In contrast, $\mathrm{Li}_{4} \mathrm{FeSbO}_{6},{ }^{35}$ like Li-rich NMC shows both $\left(\mathrm{O}_{2}\right)^{n-}$ formation and $\mathrm{O}_{2(\mathrm{~g})}$ release, while for the $\mathrm{Ru}$ and Ir-based phases there is solely formation of $\left(\mathrm{O}_{2}\right)^{n-}$ uniformly throughout the bulk. ${ }^{10}$ From this set of results, a tentative correlation appears to exist between the oxidation voltage and the stability of $\left(\mathrm{O}_{2}\right)^{n-}$ against recombination into $\mathrm{O}_{2}$, which becomes enhanced at higher voltages (Fig. 2.a). This new finding is triggering a new mindset among researchers that we are not limited by only cationic redox processes in conceiving insertion electrodes.

\section{Anionic redox processes in oxygen electrocatalysts}

The relative position of the metal $d$ and oxygen $p$ bands of metal oxides can also play an important role in catalysing water splitting. In a simplistic view, the metal center of the electrocatalyst acts as the absorption site and redox center, allowing for electron transfers during the water oxidation (Fig. 2c). This implies that for the OER at $1.23 \mathrm{~V}$ vs. RHE, the redox center needs to provide or accept electrons with an energy close to the one corresponding to the thermodynamic potential of oxygen in water in order to minimize the associated overpotential (Fig. 2.b). The perovskite and rutile families, due to their rich crystal chemistry, have been used as the perfect playground for tuning physical parameters governing the metal oxide electronic properties. ${ }^{22,37-40} \mathrm{~A}$ consensus is met between theoretical and experimental results with oxides attaining high catalytic activity for OER using less electropositive metals $(\mathrm{Cr}<\mathrm{Mn}<\mathrm{Fe}<\mathrm{Co} \sim \mathrm{Ni})^{14,39,41,42}$ of high oxidation states. ${ }^{22,37,41}$ Moreover, enhanced OER activity has been observed when increasing both the M-O covalency ${ }^{43}$ and the computed center of the oxygen $p$ band vs the Fermi level in a set of fully oxidized cobalt-based perovskites. ${ }^{22}$ Nevertheless, for late transition metal ions in the valence state of $3+/ 4+$, the metal $d$ band enters the oxygen $p$ band and the redox center of the catalyst is no longer defined by only the metal. Eventually, in the case of activating anionic redox, oxygen can be evolved via the oxidation of lattice oxygen at a potential higher than $1.23 \mathrm{~V}$ vs. RHE, which has been observed for today's most active OER oxide catalysts (Fig. 2d). ${ }^{17,19,44}$ Therefore, the OER activity is continuously enhanced when switching from a largely cationic redox (first scenario in Figure $2 b$ ) to catalysts that activate anionic redox (second scenario in Fig. 2b). Bearing in mind that the (O-O) bond formation is often found to be rate limiting for the OER on the surface of transition metal oxides (TMO) (step 2 in Fig. 2c), ${ }^{14}$ this trend indirectly translates to the ease for two $\mathrm{O}^{-}$radicals to form an (O-O) bond on the surface of highly covalent catalysts (step 2 in Fig. 2d). Therefore, OER mechanisms for TMO made of ionocovalent metal-ligand bonds can significantly differ from metals studied traditionally by the heterogeneous catalysis community and often cannot be described by the classical approach (Fig. 2c and $2 \mathrm{~d}){ }^{19,44,45}$

The question is then to understand when the anionic redox and the lattice oxygen release occur. Remarkably, one can note that above $\sim 4.3 \mathrm{~V}$ vs $\mathrm{Li}^{2} / \mathrm{Li}^{+}$, which corresponds to $\mathrm{E}^{\circ}\left(\mathrm{O}_{2} / \mathrm{O}^{2-}\right)$ in aprotic solvent, an irreversible loss of $\mathrm{O}_{2(\mathrm{~g})}$ is found for layered compounds such as Li-rich NMC, whereas below that potential, reversible $\left(\mathrm{O}_{2}\right)^{\mathrm{n}-\mathrm{r}}$ species can be observed for $\mathrm{Li}_{2} \mathrm{Ru}_{1-\mathrm{y}} \mathrm{Sn}_{\mathrm{y}} \mathrm{O}_{3}$ (Fig. 2.a). The same behaviour can be found for OER catalysts where lattice oxygen is evolved above the standard potential of oxygen $\mathrm{E}^{\circ}\left(\mathrm{O}_{2} / \mathrm{O}^{2-}\right)$ in water $(1.23 \mathrm{~V}$ vs. RHE). This observation suggests that at a potential below $\mathrm{E}^{\circ}\left(\mathrm{O}_{2} / \mathrm{O}^{2-}\right)$, the oxide electronic structure governs the formation of $\left(\mathrm{O}_{2}\right)^{\mathrm{n}-}$ species, while for a potential above which $\mathrm{O}_{2(\mathrm{~g})}$ is thermodynamically stable, bulk or surface oxygenated species are prone to be further oxidized and gaseous oxygen to be released. It is then expected that $\left(\mathrm{O}_{2}\right)^{\mathrm{n}-}$ species will not be stable at a potential above $\sim 4.3 \mathrm{~V} \mathrm{vs} \mathrm{Li}^{+} / \mathrm{Li}$. This observation is also critical 
for the understanding of the OER mechanism and the catalyst stability under OER conditions at different $\mathrm{pH}$. Additionally, the stability of the organic electrolyte against these species will require further investigation.

a)

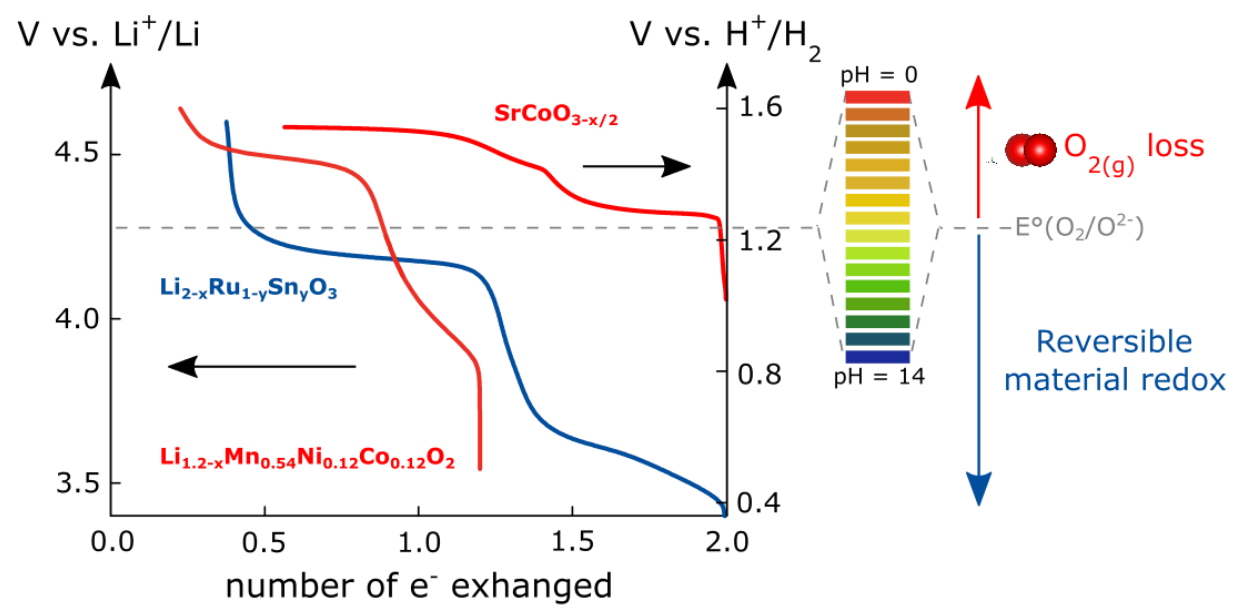

b)

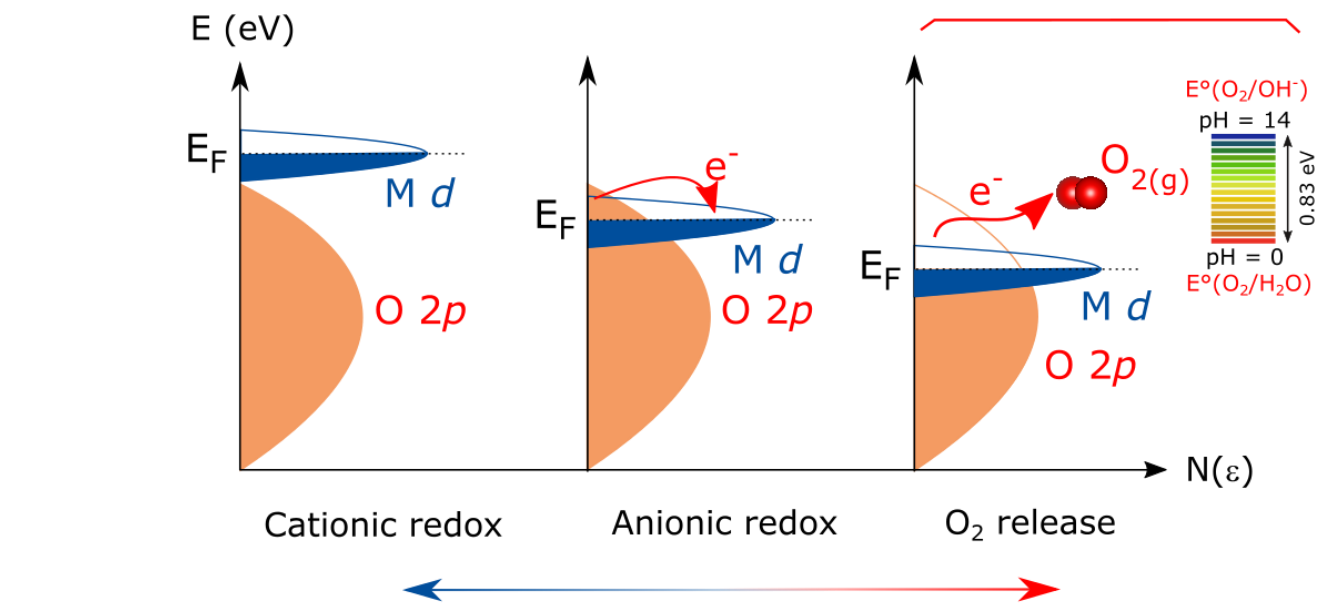

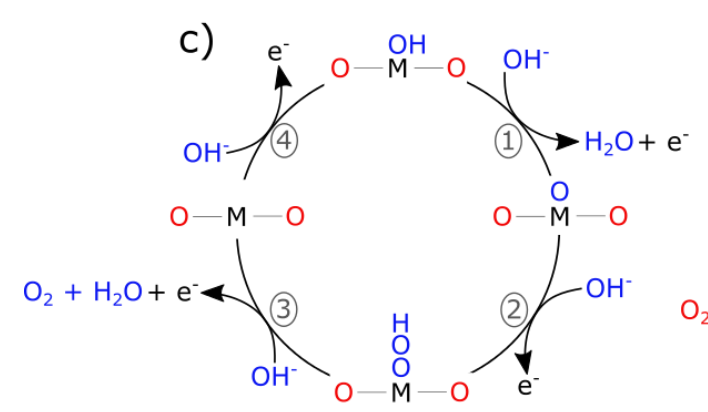

Classical OER mechanism

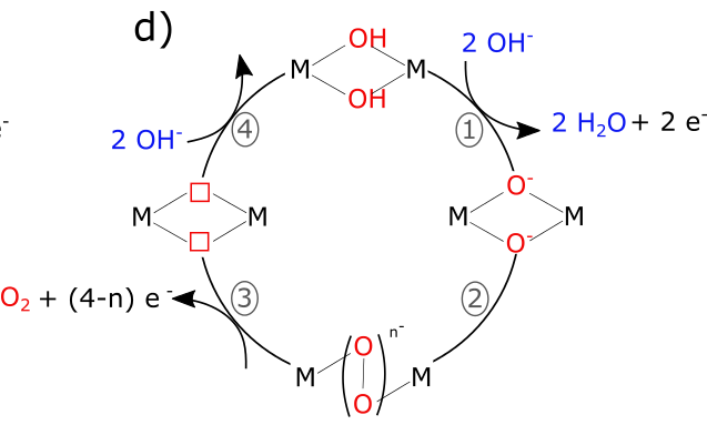

Lattice oxygen OER mechanism

Figure. 2. Anionic redox process for OER and $\mathrm{LIB}$ materials. a) Voltage profile vs $\mathrm{Li}^{+} / \mathrm{Li}$ for $\mathrm{Li}_{2-}$ ${ }_{\mathrm{x}} \mathrm{Ru}_{1-\mathrm{y}} \mathrm{Sn}_{\mathrm{y}} \mathrm{O}_{3}$ and $\mathrm{Li}_{1.2-\mathrm{x}} \mathrm{Mn}_{0.54} \mathrm{Ni}_{0.12} \mathrm{Co}_{0.12} \mathrm{O}_{2}$ during the oxidation process in aprotic solvent (EC:DMC $1 \mathrm{M} \mathrm{LiPF}_{6}$ ) compared to the voltage profile vs. $\mathrm{H}^{+} / \mathrm{H}_{2}$ for $\mathrm{SrCoO}_{3-\mathrm{x} / 2}$ during the oxidation in alkaline solution $(1 \mathrm{M} \mathrm{KOH}$ at $\mathrm{pH}=14)$. This scheme highlights the dependence of the $\left(\mathrm{O}_{2}\right)^{\mathrm{n}-}$ species stability on the oxygen standard potential in solution. b) Schematic representation of the energy level vs density of states showing the respective motion of the metal $d$ band with respect to the oxygen $p$ band in going from cationic to anionic redox processes and then $\mathrm{O}_{2}$ release. In c) the classical 4 concerted 
proton-electron transfer (PCET) OER mechanism, which rate-determining step is often found to involve the formation of $\mathrm{OOH}$ intermediate ${ }^{14}$ that is facilitated by increasing the covalence of the TM$\mathrm{O}$ bond. ${ }^{15,22}$ is shown and is compared in d) with the idealized OER mechanism based on the direct pairing of two lattice oxygen which is made possible by the anionic redox process. Existing experimental evidence supporting such mechanism for OER catalyst originate from i) in-situ Raman spectroscopy with the detection of $(\mathrm{O}-\mathrm{O})^{\mathrm{n}}$ species ${ }^{46}$ and of the loss of lattice $\mathrm{O}_{2(\mathrm{~g})}$ (step 3) as deduced recently by coupling isotopic ${ }^{18} \mathrm{O}$ labelling with mass spectrometry measurements. ${ }^{44,45,47,48} \mathrm{We}$ also show on the side two color bars to highlight the modification of the $\mathrm{O}_{2} / \mathrm{O}^{2-}$ redox couple as a function of $\mathrm{pH}$, and hence its importance on the $\mathrm{O}_{2}$ release.

The apparent synergy in oxygen redox of lithium insertion oxides and oxide catalysts rooted in the bulk oxide electronic structure opens new venues for designing catalysts for oxygen electrocatalysis. Recent studies have begun to explore the possibility of tuning the redox level of lithium insertion layered compounds for OER, ${ }^{4950}$ where some exhibit markedly high activities. ${ }^{51}$ Whereas the classical vision adopted for heterogeneous catalysts focuses on the (O-O) bonds formation on the surface of the catalyst, open structures such as layered compounds for which water can penetrate in between the $\mathrm{MO}_{2}$ planes might exhibit high activities by rendering bulk $\left(\mathrm{O}_{2}\right)^{\mathrm{n}-}$ species active for the OER. It will then be important to further understand i) the kinetics associated with the lattice oxygen release, ii) the chemical surface reconstruction process driven by water and iii) the structural reorganization triggered by the former. Finally, the choice of $\mathrm{pH}$ in optimizing the OER performances will become pivotal. These are exciting questions to explore. Answers would provide valuable insights on the effect of anionic redox on the efficiency of the OER process. Moreover, they will enable the setting of a platform to explore more complex structures such as the one observed for electrodeposited oxide clusters, which were reported by Nocera and coworkers to show oxygen release. ${ }^{17}$

Exploiting this opportunity further will call for crystal chemistry considerations to promote the formation of $(\mathrm{O}-\mathrm{O})$ bonds in bulk oxides, bearing in mind that they form more easily for lowdimensional layered oxides than in the 3D structures such as cubic perovskites that have been extensively studied so far. For the latter, the rigidity of the 3D network made of corner-shared octahedra does not allow for the bulk formation of such $\mathrm{O}-\mathrm{O}$ bonds, in contrast to the truncated surface octahedra that provide sufficient flexibility to the M-O bond to form labile O-O bonds. Hexagonal perovskites of general formula $\mathrm{Ln}_{2} \mathrm{Sr}_{2} \mathrm{MO}_{7+\delta}(\mathrm{M}=\mathrm{Ru}$, Ir) that contain bulk peroxide ions are so far the only exception. ${ }^{52-54}$ To broaden the spectrum of perovskite compounds hosting O-O bonding, several paths can be envisioned. The exploration of nickelate and cuprate perovskites appears as a fertile ground since these $3 d$-metals are known to accommodate the formation of ligand holes (high $\mathrm{T}_{\mathrm{c}}$ cuprates or $\mathrm{La}_{2} \mathrm{NiO}_{4+\delta}$ for instance). ${ }^{29,55}$ Alternatively, perovskites using both late transition metals and high oxidation states, so as to increase the $\mathrm{M} d$ - and $\mathrm{O} p$-band overlap, are attractive but difficult to obtain unless new synthetic routes are developed or new crystal structures unraveled. Lastly, oxides with lower dimensionality such as the double perovskites $\mathrm{LnBaCo}_{2} \mathrm{O}_{5+\delta}$, Ruddlesden-Popper $\mathrm{Ln}_{\mathrm{n}+1} \mathrm{M}_{\mathrm{n}} \mathrm{O}_{3 \mathrm{n}+1}$ phases (Ln being a rare-earth and $\mathrm{M}$ being a late transition metal) or even quadrupole perovskites such as $\mathrm{AA}^{\prime} \mathrm{M}_{4} \mathrm{O}_{12}\left(\mathrm{CaCu}_{3} \mathrm{Fe}_{4} \mathrm{O}_{12}\right.$ for instance, where $\mathrm{Cu}^{2+}$ is in the vicinity of the polyhedral network) could provide another playground to design OER catalysts capable of forming (O-O) species. In short, a totally new, unexplored ground awaits us.

Further looking in the broad interest of the anionic redox process, one could see a light within the near future with the field of pseudocapacitors. Let's describe in a simplistic view pseudocapacitors as core-shell particles with the nanometer shell producing the redox activity. Well-known examples enlisting $\mathrm{MnO}_{2}, \mathrm{RuO}_{2}$ or $\mathrm{FeWO}_{4}$ rely on cationic redox couples. Expanding this view could envision the possibility of having an anionic redox process with $\left(\mathrm{O}_{2}\right)^{\mathrm{n}-\mathrm{s}}$ species formed on the surface. ${ }^{56}$ From this simplistic picture, it appears that TMO showing detectable capacitance could also display 
enhanced performances for water splitting. This could be an indirect way to screen potential candidates in our quest for more active catalysts, an approach being presently undertaken.

\section{Extension of the metal-ligand chemical intuition for other reactions}

At this stage a legitimate question regards whether this new vision of classifying electrocatalysts by their redox center holds for other type of reactions. The first that comes to mind is the other half reaction of water splitting, namely the hydrogen evolution reaction (HER) that reduces protons from water to form $\mathrm{H}_{2(\mathrm{~g})}$. This implies, based on our understanding developed for OER catalysts made of late transition metal oxides, the need for compounds made of more reductive MetalLigand bonds so as to provide a lower redox potential and better stability upon reduction (Fig. 3). A simple strategy would consist in using a ligand with lower electronegativity, such as sulphur or selenium, coupled with an early transition metal. This concept previously employed to tune the $\mathrm{Li}^{+}$ insertion potential of positive electrodes for LIBs gives rise to materials such as $\mathrm{MS}_{2}$ (with $\mathrm{M}$ being an early transition metals such as Ti, Mo or $\mathrm{W}$ ), characterized by a redox potential $\sim 1.5-2 \mathrm{~V}$ lower than for TMO. Hence, with a redox potential well aligned with the thermodynamic potential for HER, $\mathrm{MoS}_{2}$ or other chalcogenides such as $\mathrm{WS}_{2}$ or $\mathrm{TiS}_{2}$ are currently considered as state-of-the-art nonprecious HER catalysts. ${ }^{57-59}$ Following this line of thinking, both fields can be reconciled by observing that the enthalpy of the reaction $\mathrm{A}^{+}+\mathrm{e}^{-}+\mathrm{MX}_{\mathrm{n}} \rightarrow \mathrm{AMX}_{\mathrm{n}}$ (with A being Li or $\mathrm{H}$ ) is the key factor governing the surface reduction and the HER kinetics $\left(\Delta \mathrm{G}_{\mathrm{H}^{*}}\right)$, as well as the bulk $\mathrm{Li}^{+}$insertion potential $\left(-\mathrm{nFE}_{\text {cell }}=\Delta_{\mathrm{r}} \mathrm{G}\right)$.

This second example emphasizes that oxidizing Metal-Ligand bonds are appropriate for highpotential applications, and that more reducing Metal-Ligand bond would be employed as electrocatalysts for a low-potential reduction reaction. Such a simple chemical intuition also holds for the design of phosphides ${ }^{60}$ carbides $^{61}$ or nitrides ${ }^{62}$ as HER electrocatalysts. It is also worth noting that $3 d$-metal phosphide phases $\left(\mathrm{Ex} ; \mathrm{Li}_{7} \mathrm{MnP}_{4}\right)$ were previously proposed as negative electrodes for Li-ion batteries due to their staggering capacity associated with the redox activity of the phosphorus network, ${ }^{63,64}$ raising the question of the ligand redox participation to the HER mechanism.

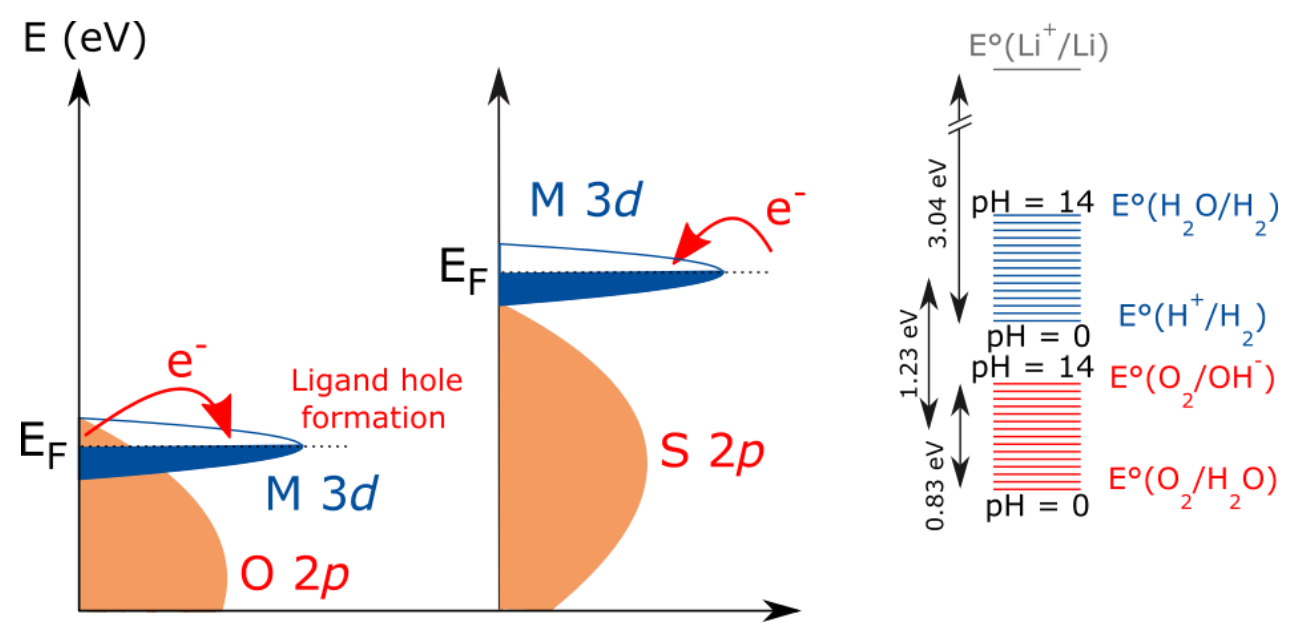

Figure 3. Electrocatalysts with low redox potential for HER. Schematic showing the design strategy for materials with lower redox potential than transition metal oxides to be used as HER electrocalatysts. For that, a ligand such as sulphur with lower electronegativity than oxygen is preferred and coupled with an early transition metal.

\section{Conclusion}


Through this commentary, we tried to describe the cross-disciplinary interest provided by the recently established anionic redox activity in oxides, together with the transformative approach that it offers to create/design novel battery and energy-related materials such as electrocatalysts for water splitting. An increasing number of papers dealing with either Li- or Na-based compounds showing extra capacities and referring to anionic redox chemistry are appearing, and others are in the pipeline. Additionally, we provided insights into the impact that anionic redox could have in designing new heterogeneous electrocatalysts. This is the beginning of a new direction in materials science, with the $\mathrm{M} d$ - and $\mathrm{X} p$-band mixing at the center of this new approach. At this stage, a close integration with computational theory is essential not only for establishing a hybridization indicator for recognizing cation-anion pairs and host structures that support anionic redox activity, but also for identifying a reliable parameter controlling the stability of electrochemically-driven oxygenated $\left(\mathrm{O}_{2}\right)^{n-}$ species against recombination into gaseous $\mathrm{O}_{2}$ at high potential. Lastly, the discovery of the anionic redox concept calls for new advances in characterization techniques to monitor the reversible formation of superoxo/peroxo-like $\left(\mathrm{O}_{2}\right)^{n-}$ species for both electrodes and electrocatalyst materials. For that, gas analysis coupled with isotopic labelling will play a critical role for the detection of lattice oxygen loss. Moreover, synchrotron based techniques such as XPS, XAS or $\mathrm{XES}^{23}$ will enable for a fine understanding of the electronic structure of oxides.

\section{$\underline{\text { References: }}$}

1. T. Ohzuku, Y. M. Layered lithium insertion material of LiCo1/3Ni1/3Mn1/3O2 for lithium-ion batteries. Chem. Lett. 7, 642-643 (2001).

2. Thackeray, M. M. et al. Li2MnO3-stabilized LiMO2 (M = Mn, Ni, Co) electrodes for lithiumion batteries. J. Mater. Chem. 17, 3112 (2007).

3. Lu, Z., Beaulieu, L. Y., Donaberger, R. a., Thomas, C. L. \& Dahn, J. R. Synthesis, Structure, and Electrochemical Behavior of Li[NixLi1/3-2x/3Mn 2/3-x/3]O2. J. Electrochem. Soc. 149, A778 (2002).

4. Thackeray, M. M., Johnson, C. S., Vaughey, J. T., Ha, N. \& Hackney, S. A. Advances in manganese-oxide "composite" electrodes for lithium-ion batteries. J. Mater. Chem. 15, 2257 (2005).

5. Sathiya, M. et al. Reversible anionic redox chemistry in high-capacity layered-oxide electrodes. Nat. Mater. 12, 827-35 (2013).

6. Sathiya, M. et al. Electron paramagnetic resonance imaging for real-time monitoring of Li-ion batteries. Nat. Commun. 6, 6276 (2015).

7. Tarascon, J. M. et al. In Situ Structural and Electrochemical Study of Ni1-x CoxO2 Metastable Oxides Prepared by Soft Chemistry. J. Electrochem. Soc. 420, 410-420 (1999).

8. Rivadulla, F., Zhou, J.-S. \& Goodenough, J. B. Chemical, structural, and transport properties of $\mathrm{Na} 1-\mathrm{x} \mathrm{CoO}$ 2. Phys. Rev. B 68, 075108 (2003).

9. Foix, D., Mariyappan, S., McCalla, E., Tarascon, J.-M. \& Gonbeau, D. XPS study of cationic and anionic redox processes in high capacity $\mathrm{Li}$-ion battery layered-oxide electrodes. 
10. McCalla, E. et al. Visualization and impact of O-O peroxo-like dimers in high capacity layered oxides for Li-ion batteries. (2015).

11. Yabuuchi, N. et al. High-capacity electrode materials for rechargeable lithium batteries: Li3NbO4-based system with cation-disordered rocksalt structure. Proc. Natl. Acad. Sci. U. S. A. 1-6 (2015). doi:10.1073/pnas.1504901112

12. Rozier, P. et al. Anionic redox chemistry in Na-rich Na2Ru1-ySnyO3 positive electrode material for Na-ion batteries. Electrochem. commun. 53, 29-32 (2015).

13. Nørskov, J. K. et al. Origin of the Overpotential for Oxygen Reduction at a Fuel-Cell Cathode. J. Phys. Chem. B 108, 17886-17892 (2004).

14. Man, I. C. et al. Universality in Oxygen Evolution Electrocatalysis on Oxide Surfaces. ChemCatChem 3, 1159-1165 (2011).

15. Suntivich, J., May, K. J., Gasteiger, H. a, Goodenough, J. B. \& Shao-Horn, Y. A perovskite oxide optimized for oxygen evolution catalysis from molecular orbital principles. Science 334, 1383-5 (2011).

16. Suntivich, J. et al. Design principles for oxygen-reduction activity on perovskite oxide catalysts for fuel cells and metal-air batteries. Nat. Chem. 3, 546-550 (2011).

17. Surendranath, Y., Kanan, M. W. \& Nocera, D. G. Mechanistic Studies of the Oxygen Evolution Reaction by a Cobalt-Phosphate Catalyst at Neutral pH. J. Am. Chem. Soc. 132, $16501-16509$ (2010).

18. Mavros, M. G. et al. What Can Density Functional Theory Tell Us about Artificial Catalytic. Inorg. Chem. 53, 6386-6397 (2014).

19. De Faria, L. A., Boodts, J. F. C. \& Trasatti, S. Electrocatalytic properties of ternary oxide mixtures of composition Ruo0.3Ti(0 .7-x) CexO2 : oxygen evolution from acidic solution. $J$. Appl. Electrochem. 26, 1195-1199 (1996).

20. May, K. J. et al. Influence of oxygen evolution during water oxidation on the surface of perovskite oxide catalysts. J. Phys. Chem. Lett. 3, 3264-3270 (2012).

21. Risch, M. et al. Structural Changes of Cobalt-Based Perovskites upon Water Oxidation Investigated by EXAFS. J. Phys. Chem. C 117, 8628-8635 (2013).

22. Grimaud, A. et al. Double perovskites as a family of highly active catalysts for oxygen evolution in alkaline solution. Nat. Commun. 4, 2439 (2013).

23. Hong, W. T. et al. Probing LaMO 3 Metal and Oxygen Partial Density of States Using X-ray Emission, Absorption, and Photoelectron Spectroscopy. J. Phys. Chem. C 119, 2063-2072 (2015).

24. Lee, Y.-L., Kleis, J., Rossmeisl, J., Shao-Horn, Y. \& Morgan, D. Prediction of solid oxide fuel cell cathode activity with first-principles descriptors. Energy Environ. Sci. 4, 3966-3970 (2011). 
25. Mueller, D. N., Machala, M. L., Bluhm, H. \& Chueh, W. C. Redox activity of surface oxygen anions in oxygen-deficient perovskite oxides during electrochemical reactions. Nat. Commun. 6, 6097 (2015).

26. Goodenough, J. B. \& Kim, Y. Challenges for Rechargeable Li Batteries. Chem. Mater. 22, 587-603 (2010).

27. Rouxel, J. Anion-Cation Redox Competition and the Formation of New Compounds in Highly Covalent Systems. Chem. - A Eur. J. 2, 1053-1059 (1996).

28. Blandeau, L., Ouvrard, G., Calage, Y., Brec, R. \& Rouxel, J. Transition-metal dichalcogenides from disintercalation processes. Crystal structure determination and Mossbauer study of Li2FeS2 and its disintercalates LixFeS2 $(0.2<\mathrm{x}<2)$. J. Phys. C ... 4271, 4271-4281 (1987).

29. Nücker, N., Fink, J., Fuggle, J. ., Durham, P. . \& Temmerman, W. . Evidence for holes on oxygen sites in the high-Tc superconductors La2-xSrxCuO4 and YBa2Cu3O7-y. Phys. Rev. B 37, 5158-5163 (1988).

30. Saubanère, M., McCalla, E., Tarascon, J.-M. \& Doublet, M.-L. The intriguing question of anionic redox in high-energy density cathodes for Li-ion batteries. Energy Environ. Sci. (2015). doi:10.1039/C5EE03048J

31. Saubanère, M., McCalla, E., Tarascon, J.-M. \& Doublet, M.-L. The intriguing question of anionic redox in high-energy density cathodes for Li-ion batteries. Energy Environ. Sci. (2015).

32. Koga, H., Croguennec, L. \& Me, M. Operando X-ray Absorption Study of the Redox Processes Involved upon Cycling of the Li-Rich Layered Oxide Li1.20Mn0.54Co0.13Ni0.13O2 in Li Ion Batteries. J. Phys. Chem. C 118, 5700-5709 (2014).

33. Sathiya, M. et al. $\mathrm{Li}(4) \mathrm{NiTeO}(6)$ as a positive electrode for Li-ion batteries. Chem. Commun. 49, 11376-8 (2013).

34. McCalla, E. et al. Reversible Li-Intercalation through Oxygen Reactivity in Li-Rich Li-Fe-Te Oxide Materials. J. Electrochem. Soc. 162, A1341-A1351 (2015).

35. McCalla, E. et al. Understanding the Roles of Anionic Redox and Oxygen Release during Electrochemical Cycling of Lithium-Rich Layered Li4FeSbO6. J. Am. Chem. Soc. 137, 480414 (2015).

36. Sathiya, M. et al. Origin of voltage decay in high-capacity layered oxide electrodes. Nat. Mater. 14, 230-238 (2015).

37. Wattiaux, a. Electrolytic Oxygen Evolution in Alkaline Medium on $\mathrm{La}[\mathrm{sub} 1-\mathrm{x}] \mathrm{Sr}[\mathrm{sub}$ x]FeO[sub 3-y] Perovskite-Related Ferrites. J. Electrochem. Soc. 134, 1714 (1987).

38. Bockris, J. O. \& Otagawa, T. Mechanism of oxygen evolution on perovskites. J. Phys. Chem. 87, 2960-2971 (1983).

39. Bockris, J. O. \& Otagawa, T. The electrocatalysis of oxygen evolution on perovskites. $J$ Electrochem Soc 131, 290-302 (1984). 
40. Grimaud, A. et al. Oxygen Evolution Activity and Stability of Ba 6 Mn 5 O 16, Sr 4 Mn 2 $\mathrm{CoO} 9$, and $\mathrm{Sr} 6 \mathrm{Co} 5 \mathrm{O} 15$ : The In fl uence of Transition Metal Coordination. J. Phys. Chem. C 117, 25926-25932 (2013).

41. Suntivich, J., May, K. J., Gasteiger, H. A., Goodenough, J. B. \& Shao-Horn, Y. A perovskite oxide optimized for oxygen evolution catalysis from molecular orbital principles. Science (80-. ). 334, 1383-1385 (2011).

42. Hong, W. et al. Toward the rational design of non-precious transition metal oxides for oxygen electrocatalysis. Energy Environ. Sci. 8, 1404-1427 (2015).

43. Suntivich, J. et al. Estimating Hybridization of Transition Metal and Oxygen States in Perovskites from O K-edge X-ray Absorption Spectroscopy. J. Phys. Chem. C 118, 1856-1863 (2014).

44. Wohlfahrt-Mehrens, M. \& Heitbaum, J. Oxygen evolution on Ru and RuO2 electrodes studied using isotope labelling and on-line mass spectrometry. J. Electroanal. Chem. 237, 251-260 (1987).

45. Surendranath, Y., Kanan, M. W. \& Nocera, D. G. Mechanistic Studies of the Oxygen Evolution Reaction by a Cobalt-Phosphate Catalyst at Neutral pH. 16501-16509 (2010). doi:10.1021/ja908730h.(45)

46. Trześniewski, B. J. et al. In-situ observation of active oxygen species in Fe-containing Nibased oxygen evolution catalysts: the effect of $\mathrm{pH}$ on electrochemical activity. J. Am. Chem. Soc. (2015). doi:10.1021/jacs.5b06814

47. Fierro, S., Nagel, T., Baltruschat, H. \& Comninellis, C. Investigation of the oxygen evolution reaction on $\mathrm{Ti} / \mathrm{IrO} 2$ electrodes using isotope labelling and on-line mass spectrometry. Electrochem. commun. 9, 1969-1974 (2007).

48. Diaz-Morales, O., Calle-Vallejo, F., de Munck, C. \& Koper, M. T. M. Electrochemical water splitting by gold: evidence for an oxide decomposition mechanism. Chem. Sci. 4, 2334 (2013).

49. Wang, H. et al. Bifunctional non-noble metal oxide nanoparticle electrocatalysts through lithium-induced conversion for overall water splitting. Nat. Commun. 6, 7261 (2015).

50. Maiyalagan, T., Jarvis, K. a, Therese, S., Ferreira, P. J. \& Manthiram, A. Spinel-type lithium cobalt oxide as a bifunctional electrocatalyst for the oxygen evolution and oxygen reduction reactions. Nat. Commun. 5, 3949 (2014).

51. Lee, S. W. et al. The nature of lithium battery materials under oxygen evolution reaction conditions. J. Am. Chem. Soc. 134, 16959-62 (2012).

52. Ebbinghaus, S. G., Erztoument, C. \& Marozau, I. Ln2Sr2PtO7+ $\delta$ (Ln=La, Pr, and Nd): Three new Pt-containing [AnBn-1O3n]-type hexagonal perovskites. J. Solid State Chem. 180, 3393 3400 (2007).

53. Götzfried, T., Reller, A. \& Ebbinghaus, S. G. Structural and Magnetic Properties of Hexagonal Perovskites La1.2Sr2.7MO7.33 (M = Ru, Ir) Containing Peroxide Ions. Inorg. Chem. 44, 6550-6557 (2005). 
54. Grasset, F., Dussarrat, C., Darriet, J. \& Schweitzer, A. A. Preparation, thermal stability and crystal structure of a new ruthenium(V) oxide containing peroxide ions : $\mathrm{Ba} 2 \mathrm{Ru} 5 \mathrm{O} 9(\mathrm{O} 2)$. Structural relationships to the hexagonal-type perovskite. J. Mater. Chem. 7, 1911-1915 (1997).

55. Demourgues, A. et al. Electrochemical preparation and structural characterization of La2NiO4+d phases $(0<\mathrm{d}<0.25)$. J. Solid State Chem. 105, 458-468 (1993).

56. Mefford, J. T., Hardin, W. G., Dai, S., Johnston, K. P. \& Stevenson, K. J. Anion charge storage through oxygen intercalation in LaMnO3 perovskite pseudocapacitor electrodes. Nat. Mater. 13, 726-32 (2014).

57. Hinnemann, B. et al. Biomimetic hydrogen evolution: MoS2 nanoparticles as catalyst for hydrogen evolution. J. Am. Chem. Soc. 127, 5308-9 (2005).

58. Voiry, D. et al. Enhanced catalytic activity in strained chemically exfoliated WS2 nanosheets for hydrogen evolution. Nat. Mater. 12, 850-5 (2013).

59. Jaramillo, T. F. et al. Identification Electrochemical of Active Edge Sites for H2 Evolution from Nanocatalysts. Science (80-. ). 317, 100-102 (2007).

60. Popczun, E. J. et al. Nanostructured Nickel Phosphide as an Electrocatalyst for the Hydrogen Evolution Reaction. J. Am. Chem. Soc. 135, 9267-9270 (2013).

61. Vrubel, H. \& Hu, X. Molybdenum Boride and Carbide Catalyze Hydrogen Evolution in both Acidic and Basic Solutions. Angew. Chemie (International ed.) 51, 12703-12706 (2012).

62. Chen, W. et al. Hydrogen-Evolution Catalysts Based on Non-Noble Metal Nickel Molybdenum Nitride Nanosheets. Angew. Chemie (International ed.) 51, 6131-6135 (2012).

63. Pralong, V., Souza, D. C. S., Leung, K. T. \& Nazar, L. F. Reversible lithium uptake by CoP 3 at low potential : role of the anion. 4, 516-520 (2002).

64. Bichat, M.-P. et al. Redox-Induced Structural Change in Anode Materials Based on Tetrahedral (MPn 4 ) x - Transition Metal Pnictides. Chem. Mater. 16, 1002-1013 (2004).

\section{Acknowledgments}

The author would like to thank Magali Gauthier, Kelsey A. Stoerzinger and Livia Giordano at MIT, Matthieu Saubanère and Marie-Liesse Doublet at the Institut Charles Gerhardt in Montpellier as well as Eric McCalla at Collège de France for fruitful discussion.

Competing financial interests: The authors declare no competing financial interests. 